\title{
Preparation and Optimization of Macroalgae-Derived Solid Acid Catalysts
}

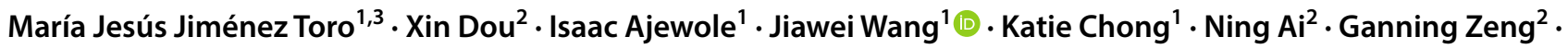 \\ Tao Chen ${ }^{4}$
}

Received: 20 January 2017 / Accepted: 4 October 2017 / Published online: 16 October 2017

(c) The Author(s) 2017. This article is an open access publication

\begin{abstract}
Solid acid catalysts were synthesized from macroalgae Sargassum horneri via hydrothermal carbonization followed by sulfuric acid sulfonation. A three-variable Box-Behnken design and optimization was used to maximize surface acidity. The optimal preparation conditions were found to be at the carbonization temperature of $217^{\circ} \mathrm{C}$, the carbonization time of $4.6 \mathrm{~h}$ and the sulfonation temperature of $108.5^{\circ} \mathrm{C}$. Under these conditions, the highest surface acidity achieved was $1.62 \mathrm{mmol} \mathrm{g}^{-1}$. Physical and chemical properties of prepared solid acid catalyst were characterized by powder X-ray diffraction (PXRD), Fourier transform infrared (FTIR) spectroscopy, and elemental analysis. The results proved the grafting of $-\mathrm{SO}_{3} \mathrm{H}$ groups on an amorphous carbon structure. The catalyst activity was evaluated by the esterification of oleic acid with methanol. The sample prepared achieved $96.6 \%$ esterification yield, which was higher than the $86.7 \%$ yield achieved by commercial Ambersyst- 15 under the same reaction conditions.
\end{abstract}

\section{Graphical Abstract}

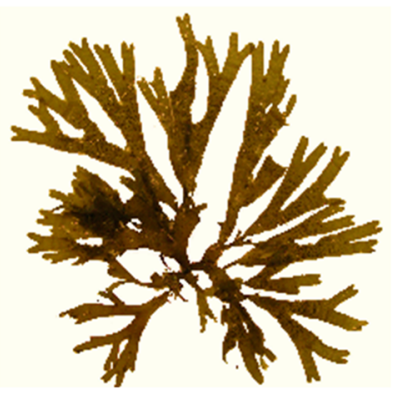

S. Horneri
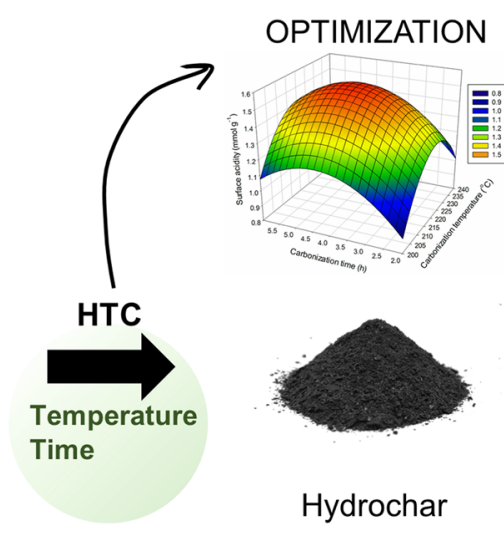

Hydrochar

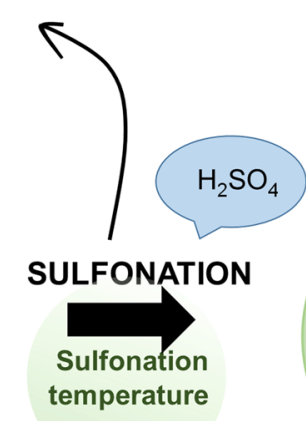

(n)

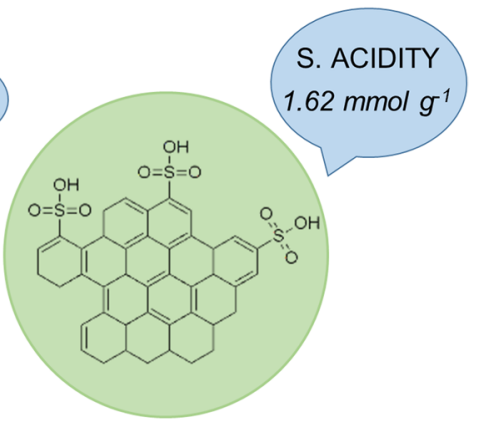

Solid Acid Catalyst

Keywords Solid acid catalyst $\cdot$ Biomass $\cdot$ Hydrothermal carbonization $\cdot$ Esterification $\cdot$ Box-Behnken design

Electronic supplementary material The online version of this article (https://doi.org/10.1007/s12649-017-0101-0) contains supplementary material, which is available to authorized users.

Jiawei Wang

j.wang23@aston.ac.uk

Extended author information available on the last page of the article

\section{Introduction}

Solid acid catalyst (SACs) are a group of widely used heterogeneous catalysts for a variety of industrial reactions. Compared to conventional liquid acid catalysts, SACs are non-corrosive, environmentally benign and present fewer 
separation and disposal problems [1, 2]. The types of SACs available include zeolites, metal oxides, ion-exchange resins, phosphates and carbonaceous materials. Recently there has been great interest in the synthesis of SACs using carbonaceous materials derived from biomass as support. A variety of biomass has been investigated, including pelletized peanut hulls, pine pellets and pine chip char [3], rice husk [4], corn straw [5], corncob [6], cassava stillage [7] bagasse [8], oil palm trunk [9], and microalgae residue [10].

Most of the biomass derived SACs are synthesized by a two-step method, e.g. a carbonization step followed by a sulfonation step. Kastner et al. [3] prepared a carbon support by pyrolysis of wood at $400-500{ }^{\circ} \mathrm{C}$ and the $-\mathrm{SO}_{3} \mathrm{H}$ groups were then introduced by reacting the carbon support with concentrated $\mathrm{H}_{2} \mathrm{SO}_{4}$ or $\mathrm{SO}_{3}$ gas. The same pyrolysis-sulfonation method has been applied to rice husk [4], corn straw [5], cassava stillage [7], bagasse [8] and oil palm trunk [9]. Another two-step route is the hydrothermal carbonizationsulfonation method, which was claimed to be less energy intensive than the pyrolysis-sulfonation route. Ma et al. [6] prepared hydrochars by hydrothermal carbonization of corncob at $120-240{ }^{\circ} \mathrm{C}$. The hydrochars were reacted with concentrated $\mathrm{H}_{2} \mathrm{SO}_{4}$ at $60-150{ }^{\circ} \mathrm{C}$ to obtain SACs. Magnetic SACs were prepared using the same route from banana peel feedstock [11]. Apart from the two-step method, one-step synthesis of SACs from biomass was also reported in the literature. SAC was synthesized by in situ partial carbonization and sulfonation of microalgae residue with sulfuric acid at $180{ }^{\circ} \mathrm{C}$ [10].

As biomass derived SAC is a relatively new research area, there is limited information on the optimization of the synthesis process. Recent years, response surface methodology (RSM) has been widely used to optimize chemical and biochemical engineering processes. RSM is a combination of mathematical and statistical techniques which can be used to evaluate the importance of process variables and improve processes [12]. Design methods such as central composite design (CCD) have been used to optimize the synthesis of $\mathrm{ZnS}: \mathrm{Cu}$ nanoparticles on activated carbon [13] and pectin extraction from banana peels [14]. Compared to CCD, another RMS-based method, Box-Behnken design, has the advantages of a reduction in the number of experiments and no experiments are performed under extreme conditions [15]. It has been successfully applied for the optimization of various processes, such as solvent extraction $[16,17]$, adsorption [18, 19], and material synthesis [20, 21].

Our previous work successfully prepared hydrochar from Sargassum horneri (S. horneri) via the hydrothermal carbonization process [22]. The principal objective of the present work was to investigate the feasibility of using the same macroalgae as a feedstock for the production of solid acid catalyst via hydrothermal carbonization and sulfonation. The prepared solid acid catalysts were characterized using various analytical methods. The catalytic activity was evaluated by the esterification of oleic acid with methanol. The second objective was to study the effects of the synthesis conditions on surface acidity. The Box-Behnken design was applied to optimize the synthesis conditions and maximize surface acidity of prepared solid acid catalysts. It was the first time that the production of solid acid catalysts from marcoalgae was investigated and optimized. The work also demonstrated that the importance of the synthesis conditions and their interaction, which would assist further scale-up of the process.

\section{Materials and Methods}

\section{Raw Material and Pre-treatment}

Adult male and female $S$. horneri plants were sampled from the rocky shore at the intertidal zones on the Nanji Islands $\left(27.4634^{\circ} \mathrm{N}, 121.0796^{\circ} \mathrm{E}\right)$, Wenzhou City, China. The composition of the raw S. horneri sample is listed in Table 1. After sampling, the plants were air-dried and delivered to the laboratory. For this study, the raw material was washed with de-ionized water, dried for $6 \mathrm{~h}$, ground and sieved through a MESH 30 sieve. The powders were dried at $110^{\circ} \mathrm{C}$ until a stable mass was reached, and then stored in a desiccator for further use.

Concentrated sulfuric acid (98\%), sodium chloride, sodium hydroxide, oleic acid and anhydrous methanol was purchased from Sinopharm (China) and used as received.

Table 1 Elemental analysis, proximate analysis and biochemical content of raw $S$. horneri sample

Content (\% dry basis, \pm standard deviation)

\begin{tabular}{lr}
\hline Elemental analysis & \\
Carbon & $35.3 \pm 0.3$ \\
Hydrogen & $5.7 \pm 0.3$ \\
Oxygen & $56.3 \pm 0.9$ \\
Nitrogen & $1.7 \pm 0.2$ \\
Sulfur & $1.0 \pm 0.1$ \\
Proximate analysis & \\
Moisture & $5.5 \pm 0.4$ \\
Volatile matter & $61.2 \pm 5.3$ \\
Fixed carbon & $21.2 \pm 1.8$ \\
Ash & $12.1 \pm 0.8$ \\
Biochemical content & \\
Cellulose & $38 \pm 3.1$ \\
Hemicellulose & $22 \pm 1.9$ \\
Lignin & $22 \pm 3.0$ \\
\hline
\end{tabular}




\section{Hydrothermal carbonization}

The hydrothermal carbonization process was conducted in a non-stirred $100 \mathrm{~mL}$ para-polyphenylene (PPL)-lined stainless steel autoclave (KH-100 mL, Shanghai Lingke Ltd., China). A total of $5 \mathrm{~g}$ of dried S. horneri powder and $50 \mathrm{~mL}$ de-ionized water was added to the autoclave. The autoclave was sealed and transferred to a preheated oven (DHG-9021 A, Hangzhou Lantian, China) at required temperature. After the reaction, the autoclave was cooled to room temperature. The solid product was filtered, washed with de-ionized water, and finally dried at $110^{\circ} \mathrm{C}$ until a stable mass was reached. The dried solid product, hydrochar (HTC), was stored in a desiccator for further treatment and characterization.

\section{Sulfonation}

A known amount of concentrated sulfuric acid (98\%) and $2 \mathrm{~g}$ of the hydrochar sample were mixed in a flask and heated at $50-130{ }^{\circ} \mathrm{C}$ for $1-8 \mathrm{~h}$. After cooling to room temperature, the mixture was diluted with $500 \mathrm{~mL}$ de-ionized water and stirred overnight. The product was filtered and thoroughly washed with de-ionized water until a $\mathrm{pH}$ of 7 was achieved. The material was then dried at $110^{\circ} \mathrm{C}$ and stored for further characterization.

\section{Optimization of Synthesis Process}

In the synthesis process, there are various parameters that have an effect on the surface acidity and thus catalyst activity. The conventional approach of experimenting with one variable at a time is time-consuming and labour intensive. The Box-Behnken experimental design method, one of the response surface methodologies, was used to find the optimum synthesis conditions to achieve highest surface acidity. The Box-Behnken design was chosen over the usual central composite design as it has the advantage to avoid treatment combinations that are extreme. The combinations of extreme temperatures and long exposure times during the HTC process could lead into the break of the carbonaceous structure and therefore loss of data. Before applying the Box-Behnken experimental design, a series of single variable experiments were carried out to identify the key experimental variables and their examinable ranges.

\section{Single Variable Experiments}

Five variables were chosen for the single variable experiments. They include the carbonization temperature, the carbonization time, the sulfonation temperature, the sulfonation time and the amount of $\mathrm{H}_{2} \mathrm{SO}_{4}$ added during the sulfonation. The ranges of the variables were selected according to literature [6]. The reaction conditions for the single variable experiments are listed in Table 2. For each variable investigated, the other variables were kept at the base conditions, which are listed in bold type in Table 2.

\section{Box-Behnken design}

The single variable experiments showed that the carbonization temperature, the carbonization time, and the sulfonation temperature were the key variables. The examinable ranges for the three variables were determined as $200-240{ }^{\circ} \mathrm{C}$, 2-6 $\mathrm{h}$ and $70-110^{\circ} \mathrm{C}$, respectively. In order to find the optimum synthesis conditions to achieve highest surface acidity, a Box-Behnken experimental design with 3 variables, 3 levels and 17 runs was applied. The number of experiments was determined according to:

$N=k^{2}+k+c_{p}$

where $k$ is the variable number and $c_{p}$ is the replicate number of the central point. The three levels were coded as -1 (low), 0 (middle) and 1 (high). Table 3 provides the variables and levels of the Box-Behnken design.

Obtained values for response variable (Y) could be approximated by a quadratic polynomial model according to the input variables $\mathrm{X}_{1}, \mathrm{X}_{2}$ and $\mathrm{X}_{3}$ :

$Y=\beta_{0}+\sum \beta_{i} X_{i}+\sum \beta_{i i} X_{i}^{2}+\sum \beta_{i j} X_{i} X_{j}+\varepsilon$

Table 2 Experimental conditions for single variable experiments

\begin{tabular}{lrrrrr}
\hline Variable & & & & & \\
\hline Carbonization temperature $\left({ }^{\circ} \mathrm{C}\right)$ & 180 & 200 & $\mathbf{2 2 0}$ & 240 & 260 \\
Carbonization time $(\mathrm{h})$ & 1 & 2 & $\mathbf{4}$ & 6 & 8 \\
Sulfonation temperature $\left({ }^{\circ} \mathrm{C}\right)$ & 50 & 70 & $\mathbf{9 0}$ & 110 & 130 \\
Sulfonation time $(\mathrm{h})$ & 1 & 2 & $\mathbf{4}$ & 6 & 8 \\
The amount of $\mathrm{H}_{2} \mathrm{SO}_{4}$ added $(\mathrm{mL})$ & 5 & 10 & 15 & $\mathbf{2 0}$ & 25
\end{tabular}

The bold numbers are the base case condition

Table 3 Experimental variables and levels in Box-Behnken design

\begin{tabular}{llrrr}
\hline Independent variables & Code & \multicolumn{2}{l}{ Level } & \\
\cline { 2 - 5 } & & \multicolumn{1}{c}{1} & \multicolumn{1}{c}{0} & \multicolumn{1}{c}{1} \\
\hline Carbonization temperature $\left({ }^{\circ} \mathrm{C}\right)$ & $\mathrm{X}_{1}$ & 200 & 220 & 240 \\
Carbonization time $(\mathrm{h})$ & $\mathrm{X}_{2}$ & 2 & 4 & 6 \\
Sulfonation temperature $\left({ }^{\circ} \mathrm{C}\right)$ & $\mathrm{X}_{3}$ & 70 & 90 & 110 \\
\hline
\end{tabular}


where $\beta_{0}$ is the offset term, $\beta_{i}$ is the linear slope and $\beta_{i i}$ reflects the quadratic effect, both for variable $X_{i}, \beta_{i j}$ represents the interaction between $X_{i}$ and $X_{j}$ and finally $\varepsilon$ is a random error [23].

The influence and significance of independent variables and the importance of their interactions were analysed using ANOVA (Analysis of Variance). Results were evaluated using statistical parameters such as degrees of freedom, p-values and F-values and determination coefficient $\left(\mathrm{R}^{2}\right)$ to assess the statistical significance of the quadratic model. Design-Expert v8.0 was used for the Box-Behnken design and data analysis.

\section{Characterizations}

FT-IR spectra were collected in the range of $400-4000 \mathrm{~cm}^{-1}$ using a potassium bromide palletization method on a Thermo-Nicolet Nexus 670 FT-IR spectrometer. A total of 64 scans were taken for each interferogram at $4 \mathrm{~cm}^{-1}$ resolution. Elemental analysis $(\mathrm{C}, \mathrm{H}, \mathrm{N}$, and $\mathrm{S})$ of the samples was carried out on a vario MACRO cube analyzer. Oxygen content was determined by difference. X-ray diffraction analysis (XRD) was conducted on a PANalytical X'Pert Pro diffractometer.

\section{Surface Acidity Analysis}

The surface acidity was measured by acid-base titration. $0.05 \mathrm{~g}$ sample and $15 \mathrm{~mL} 2 \mathrm{M} \mathrm{NaCl}$ were placed in a $50 \mathrm{~mL}$ conical flask. The mixture was mixed in an ultrasonic bath for $30 \mathrm{~min}$ to accelerate the ion-exchange. The mixture was filtered, and the filtrate was then titrated using $0.05 \mathrm{M} \mathrm{NaOH}$ aqueous solution. The surface acidity was calculated by the amount of $\mathrm{NaOH}$ solution consumed.

\section{Catalytic Activity Analysis}

The catalytic activity of the prepared samples was measured by esterification of oleic acid and methanol [5]. The esterification was carried out in a $100 \mathrm{~mL}$ three-necked flask with a magnetic stirrer and a condenser. For a typical run, the oleic acid and the catalyst were added to the reactor, followed by the introduction of methanol at the required temperature. The esterification yield was calculated by the change of the acid values before and after the reaction.

Esterification yield $(\%)=\frac{A V_{0}-A V_{1}}{A V_{0}} \times 100$ where $A V_{0}$ and $A V_{1}$ are the acid values before and after the reaction, respectively.

The acid value is defined as the weight of $\mathrm{KOH}$ in $\mathrm{mg}$ needed to neutralize the organic acids present in $1 \mathrm{~g}$ of oil. The method presented in the Chinese Standard GB/T55302005 was used to determine the acid values.

\section{Results and Discussion}

\section{Single Variable Experiments}

The effects of the five selected variables on the surface acidity were investigated by a series of single variable experiments in which only one variable was changed at a time.

The effect of the carbonization temperature on the surface acidity was investigated by varying the carbonization temperature from 180 to $260{ }^{\circ} \mathrm{C}$. The results are shown in Fig. S1a. The surface acidity increased from $0.8 \mathrm{mmol} \mathrm{g}^{-1}$ to over $1.4 \mathrm{mmol} \mathrm{g}^{-1}$ when the carbonization temperature was increased from 180 to $220^{\circ} \mathrm{C}$. However, further increasing the temperature caused a reduction in the surface acidity. At the lower temperature of $180{ }^{\circ} \mathrm{C}$, the degree of carbonization was low. Therefore the product was not suitable as a support for solid acid catalyst. With increasing carbonization temperature, further carbonization occurred and more active aromatic carbons were formed, which prefer sulfonation. The maximum value reached at $220^{\circ} \mathrm{C}$ may be due to the formation of amorphous carbon composed of small aromatic carbon sheets, to which $-\mathrm{SO}_{3} \mathrm{H}$ group can be easily bonded. However, excessive higher temperature resulted in the opposite effect on the surface acidity. Carbonization time has a similar explanation and effect on surface acidity, as shown in Fig. S1b.

Optimal sulfonation conditions was found to vary for the different materials. As can be seen in Fig. S1c, surface acidity increases from $0.6 \mathrm{mmol} \mathrm{g}^{-1}$ to $1.46 \mathrm{mmol} \mathrm{g}^{-1}$ at $90{ }^{\circ} \mathrm{C}$ and then decreased. The results obtained match other similar studies. For example, the preparation of solid acid catalyst from rice husk char [4], in which the best sulfonation temperature was also $90{ }^{\circ} \mathrm{C}$ and the catalyst showed an oleic acid conversion of $98.7 \%$ obtaining a sulfonated product with excellent stability.

The effect of the sulfonation time on the surface acidity is shown in Fig. S1d. The surface acidity was low when the sulfonation time was $1 \mathrm{~h}$. This indicates that the sulfonation reaction was not complete after $1 \mathrm{~h}$. When the sulfonation time was longer than $2 \mathrm{~h}$, it had little effect on the surface acidity, indicating that the sulfonation reaction was finished after $2 \mathrm{~h}$. Therefore no optimization was investigated further for this parameter. The sulfonation time was set as $2 \mathrm{~h}$ for further experiments. 
The effect of the amount of sulfuric acid added on the surface acidity is shown in Fig. S1e. When less than $15 \mathrm{~mL}$ sulfuric acid was added, the sulfonation reaction was not complete, resulting in a lower surface acidity. It has little effect on the surface acidity when the amount of sulfuric acid added was more than $15 \mathrm{~mL}$. No further optimization was carried out on this variable. The amount of sulfuric acid added was set as $15 \mathrm{~mL}$ for further experiments.

The preliminary single variable experiments showed that the carbonization temperature, the carbonization time and the sulfonation temperature were the key variables to achieve the highest surface acidity. These three variables were selected for further optimization using the Box-Behnken design.

\section{Box-Behnken Design}

Independent variables and their values for the Box-Behnken design used in the study are shown in Table 4 . The experiment at the central point was repeated five times. The mean surface acidity under the condition was $1.546 \pm 0.011 \mathrm{mmol} \mathrm{g}^{-1}$, indicating a good reproducibility of the process.

According to the results, the response, surface acidity (Y), can be expressed as a quadratic regression model of carbonization temperature $\left(\mathrm{T}_{\mathrm{c}}\right)$, carbonization time $\left(\mathrm{t}_{\mathrm{c}}\right)$ and sulfonation temperature $\left(\mathrm{T}_{\mathrm{s}}\right)$ :

$$
\begin{aligned}
Y= & 1.55+0.046 X_{1}+0.075 X_{2}+0.18 X_{3}-0.015 X_{1} X_{2} \\
& -0.15 X_{1} X_{3}+0.046 X_{2} X_{3}-0.31 X_{1}^{2}-0.21 X_{2}^{2}-0.12 X_{3}^{2}
\end{aligned}
$$

where

$X_{1}=\frac{T_{c}-220}{20}$

$X_{2}=\frac{t_{c}-4}{2}$

$X_{3}=\frac{T_{s}-90}{20}$

Coefficients of the model were assessed by regression analysis. Statistical analysis revealed whether it was necessary to exclude insignificant coefficients from the model. The model-fitted values of the surface acidity were calculated from Eq. (3) and listed in Table 4.

The ANOVA of the quadratic regression model is shown in Table 5. The model had an F-value of 42.58 and a p-value less than 0.0001, which indicated that the model was significant and properly fitted to the response data. The value of the determination coefficient $\left(R^{2}=0.9821\right)$ indicated that the model can explain $98.21 \%$ of the variation in the surface acidity.

The $\mathrm{p}$-values of the independent variable, sulfonation temperature $\left(\mathrm{X}_{3}\right)$, the quadratic term of the carbonization temperature $\left(\mathrm{X}_{1}^{2}\right)$ and the quadratic term of carbonization time $\left(\mathrm{X}_{2}^{2}\right)$ were all lower than 0.0001 , showing that they were the most significant variables in the quadratic expression and had the largest influence on the surface acidity.

The percentage of contribution for each individual term was calculated by the ratio of adjusted sum of squares of
Table 4 Box-Behnken runs with actual values for the three independent variables and the experimental and model-fitted responses

\begin{tabular}{llllll}
\hline Run no. & $\begin{array}{l}\text { Carbonization } \\
\text { temperature } \\
\mathrm{T}_{\mathrm{c}}\left({ }^{\circ} \mathrm{C}\right)\end{array}$ & $\begin{array}{l}\text { Carbonization } \\
\text { time } \\
\mathrm{t}_{\mathrm{c}}(\mathrm{h})\end{array}$ & $\begin{array}{l}\text { Sulfonation } \\
\text { temperature } \\
\mathrm{T}_{\mathrm{s}}\left({ }^{\circ} \mathrm{C}\right)\end{array}$ & $\begin{array}{l}\text { Surface acidity } \\
\text { Y, mmol g }\end{array}$ & \\
\cline { 5 - 6 } 1 & & & & Experimental & Model-fitted \\
2 & 240 & 6 & 90 & 1.142 & 1.136 \\
3 & 220 & 4 & 90 & 1.539 & 1.550 \\
4 & 220 & 4 & 90 & 1.533 & 1.550 \\
5 & 200 & 6 & 90 & 1.032 & 1.074 \\
6 & 240 & 2 & 90 & 1.058 & 1.016 \\
7 & 220 & 4 & 90 & 1.544 & 1.550 \\
8 & 220 & 2 & 70 & 0.953 & 1.011 \\
9 & 220 & 4 & 90 & 1.551 & 1.550 \\
10 & 200 & 4 & 70 & 0.802 & 0.744 \\
11 & 220 & 6 & 110 & 1.582 & 1.521 \\
12 & 200 & 2 & 90 & 0.887 & 0.894 \\
13 & 220 & 6 & 70 & 1.046 & 1.069 \\
14 & 240 & 4 & 70 & 1.147 & 1.136 \\
15 & 200 & 4 & 110 & 1.389 & 1.404 \\
16 & 240 & 4 & 110 & 1.128 & 1.196 \\
17 & 220 & 4 & 90 & 1.561 & 1.550 \\
\hline
\end{tabular}


Table 5 Results of ANOVA for the surface acidity

\begin{tabular}{llllrrrr}
\hline Source & Sum of squares & $\begin{array}{l}\text { Degree } \\
\text { of free- } \\
\text { dom }\end{array}$ & Mean square & F value & P value & $\begin{array}{l}\text { Percentage of } \\
\text { contribution } \\
(\%)\end{array}$ & Significant \\
\hline Model & 1.13 & 9 & 0.13 & 42.58 & $<0.0001$ & $* *$ \\
$\mathrm{X}_{1}$ & 0.017 & 1 & 0.017 & 5.63 & 0.0494 & 1.5 & $*$ \\
$\mathrm{X}_{2}$ & 0.045 & 1 & 0.045 & 15.07 & 0.0060 & 3.9 & $*$ \\
$\mathrm{X}_{3}$ & 0.27 & 1 & 0.27 & 89.87 & $<0.0001$ & 23.5 & $* *$ \\
$\mathrm{X}_{1} \mathrm{X}_{2}$ & $9.303 \times 10^{-4}$ & 1 & $9.303 \times 10^{-4}$ & 0.31 & 0.5924 & 0.1 & $*$ \\
$\mathrm{X}_{1} \mathrm{X}_{3}$ & 0.092 & 1 & 0.092 & 31.05 & 0.0008 & 8.0 & $*$ \\
$\mathrm{X}_{2} \mathrm{X}_{3}$ & $8.281 \times 10^{-3}$ & 1 & $8.281 \times 10^{-3}$ & 2.80 & 0.1381 & 0.7 & $*$ \\
$\mathrm{X}_{1}{ }^{2}$ & 0.41 & 1 & 0.41 & 137.44 & $<0.000135 .7$ & $*$ \\
$\mathrm{X}_{2}{ }^{2}$ & 0.18 & 1 & 0.18 & 59.95 & 0.0001 & 15.7 & $*$ \\
$\mathrm{X}_{3}{ }^{2}$ & 0.059 & 1 & 0.059 & 19.97 & 0.0029 & 5.1 & $*$ \\
Residual $^{2}$ & 0.021 & 7 & $2.957 \times 10^{-3}$ & & & 1.8 & \\
$\mathrm{R}^{2}$ & 0.9821 & & & & & & \\
Adjusted $\mathrm{R}^{2}$ & 0.9590 & & & & & & $*$ \\
\hline
\end{tabular}

$* p$ values $\leq 0.05, * * p$ values $\leq 0.0001$ each term to the total sum of squares. The results are shown in Table 5. Among all the terms considered, the quadratic term of the carbonization temperature $\left(\mathrm{X}_{1}^{2}\right)$ was the most influential with in the model, accounting for $35.7 \%$; followed by the sulfonation temperature $\left(\mathrm{X}_{3}, 23.5 \%\right)$ and the quadratic term of the carbonization time $\left(\mathrm{X}_{2}{ }^{2}, 15.7 \%\right)$.

Additionally, the interaction existing between the carbonization temperature and the sulfonation temperature $\left(\mathrm{X}_{1} \mathrm{X}_{3}\right)$ with a $\mathrm{p}$-value of 0.0008 and a percentage of contribution of $8.0 \%$ shows a weaker influence but still significant in the response. Other interactions like the carbonization time and temperature $\left(\mathrm{X}_{1} \mathrm{X}_{2}\right)$ showed the lowest effect on the surface acidity.

In order to gain a better understanding of the effects of the interactions between two variables on the surface acidity, the model was presented in Fig.S2-S4 as twodimensional contour plots and three-dimensional response surface curves.

Figure 1 represents the interaction between the carbonization temperature $\left(\mathrm{X}_{1}\right)$ and the carbonization time $\left(\mathrm{X}_{2}\right)$ when the sulfonation temperature was $90{ }^{\circ} \mathrm{C}$. The contour lines were circular, indicating that the interactions between the carbonization temperature and carbonization time were negligible. The maximum surface acidity that could be achieved was $1.554 \mathrm{mmol} \mathrm{g}^{-1}$ when the sulfonation temperature was $90{ }^{\circ} \mathrm{C}$

Figure 2 shows the combined effect of the carbonization temperature and the sulfonation temperature on the surface acidity at a constant carbonization time of $4 \mathrm{~h}$. The highest surface acidity achieved was $1.6 \mathrm{mmol} \mathrm{g}^{-1}$. Oval contour lines indicated a better correlation between the mentioned variables than the ones in Fig. 1 where the lines were circular. That fact was consistent with the $\mathrm{p}$-values for $\mathrm{X}_{1} \mathrm{X}_{3}$ interaction and $\mathrm{X}_{1} \mathrm{X}_{2}$ interaction obtained in ANOVA.

Figure 3 shows the interactive influence of the carbonization time and the sulfonation temperature when carbonization temperature was fixed at $220^{\circ} \mathrm{C}$. For the $3 \mathrm{D}$ response surface plot and the studied range for the sulfonation temperature, the surface acidity was clearly increasing while the sulfonation temperature increased. In terms of the carbonization time, a parabolic trend was observed. The highest value achieved was $1.62 \mathrm{mmol} \mathrm{g}^{-1}$. The $2 \mathrm{D}$ contours indicated a weak interaction between the studied variables.

\section{Validation of the Model}

According to the model, the predicted maximum surface acidity was $1.638 \mathrm{mmol} \mathrm{g}^{-1}$ when the carbonization temperature is $217.0^{\circ} \mathrm{C}$, the carbonization time is $4.6 \mathrm{~h}$ and the sulfonation temperature is $108.0^{\circ} \mathrm{C}$. In order to validate the adequacy of the model, three experiments were carried out at the predicted optimum condition. The average surface acidity obtained in the three validation experiments was $1.615 \mathrm{mmol} \mathrm{g}^{-1}$, which was in good agreement with the predicted maximum, with an error of $1.4 \%$. The validation result indicated that the model developed by the BoxBehnken was accurate.

\section{Characterizations of the Prepared Solid Acid Catalysts}

The hydrochar and sulfonated hydrochar prepared at the optimum condition were named as HTC and HTC-S. The two samples and the raw S. horneri were characterized by 
Fig. 1 Response surface and contour plots for the effects of the carbonation time and the carbonation temperature on the surface acidity
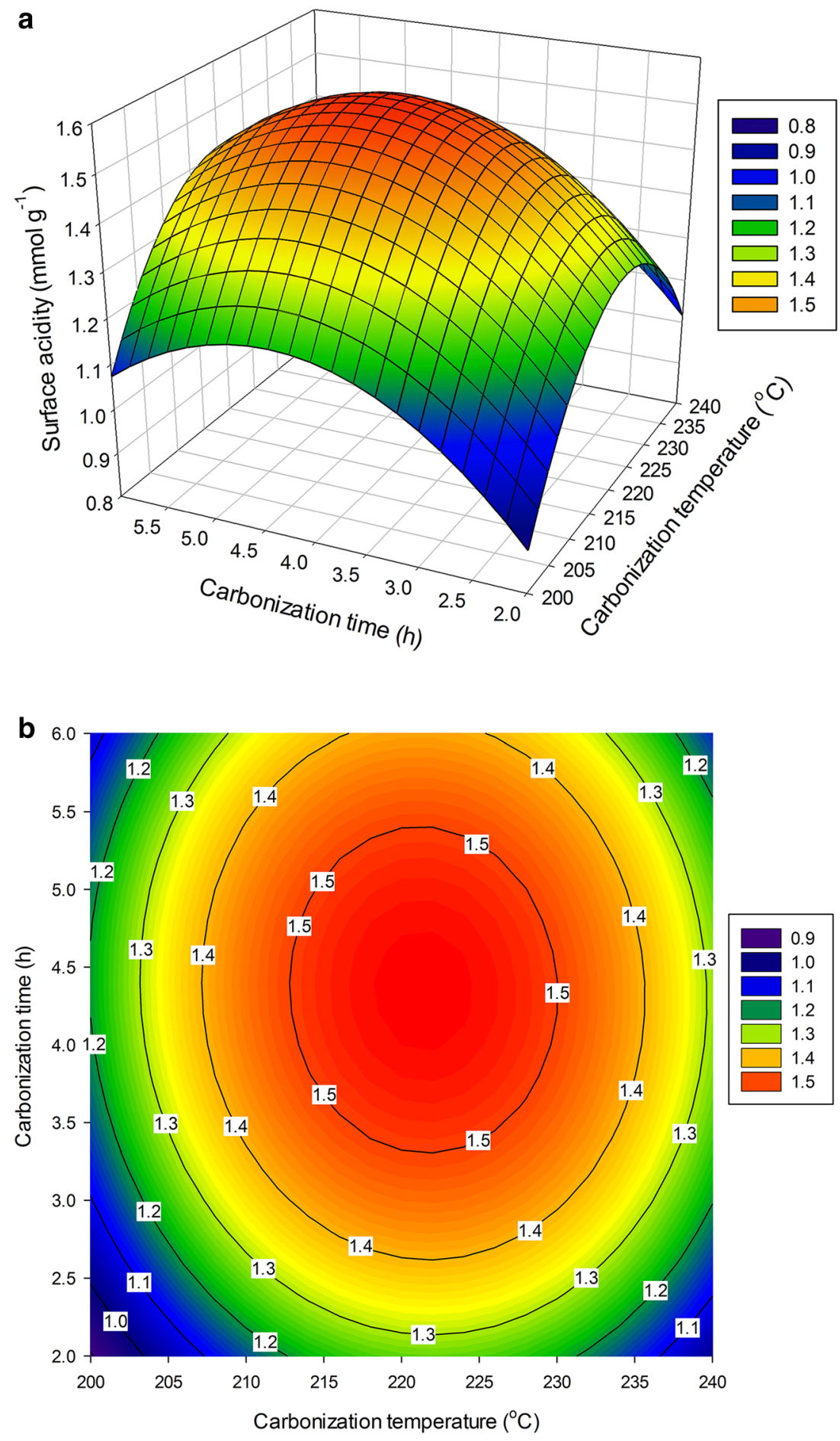

various technologies, including elemental analysis, FT-IR and XRD, in order to understand their physical and chemical properties.

The results from the elemental analysis of raw S. horneri, hydrochar (HTC) and sulfonated hydrochar (HTC-S) are listed in Table 6. After hydrothermal carbonization, the carbon content increased while hydrogen and oxygen contents reduced as expected. The sulphur content remained unchanged. After sulfonation, the sulphur and oxygen contents increased from 1.0 to 5.4 and $41.0-46.8 \%$, respectively. 
Fig. 2 Response surface and contour plots for the effects of the carbonation temperature and the sulfonation temperature on the surface acidity
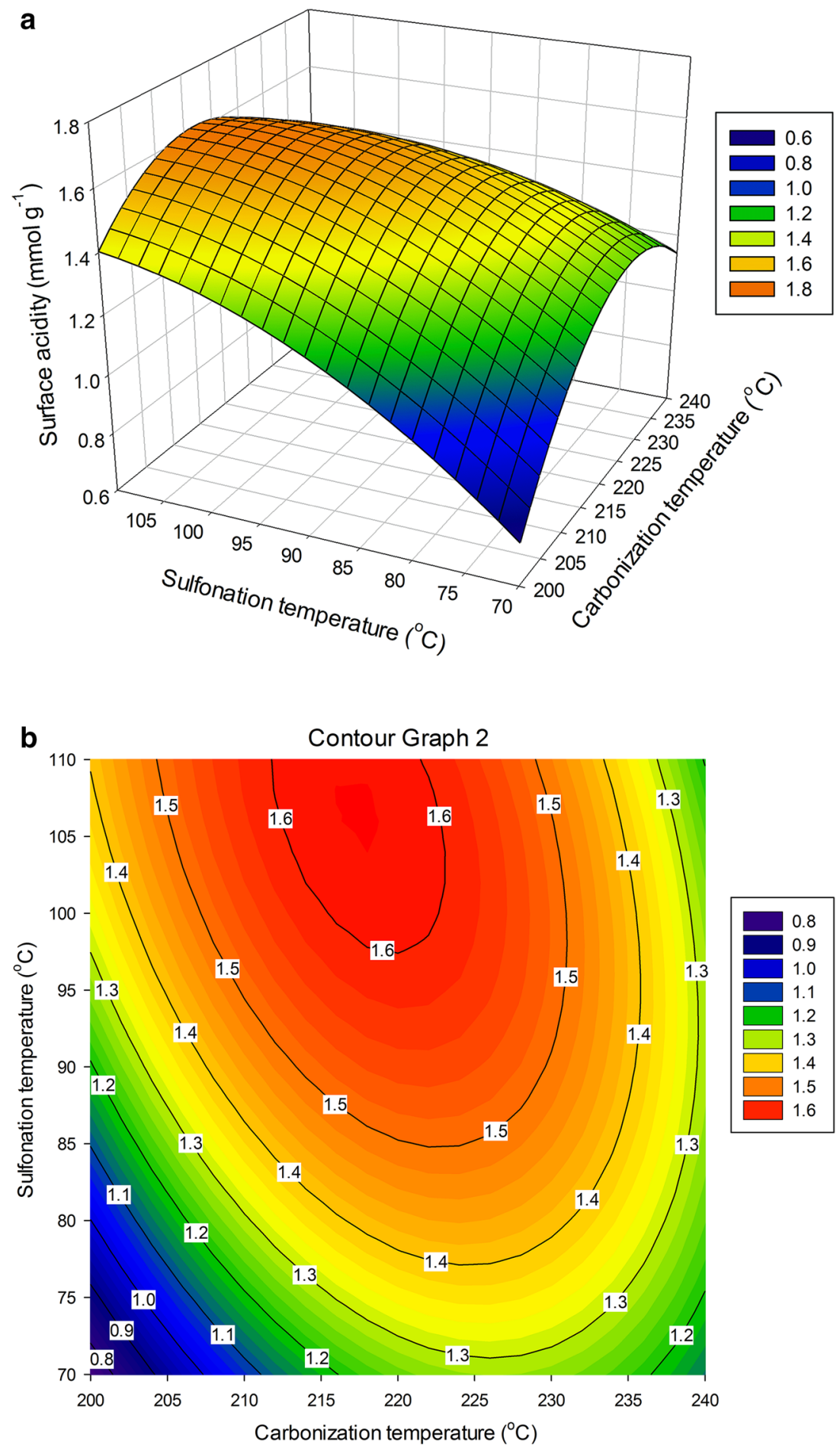

It indicated that the $-\mathrm{SO}_{3} \mathrm{H}$ groups were successfully introduced on the hydrochar through sulfonation procedure.

The FT-IR spectra of hydrochar and sulfonated hydrochar were used to examine the surface functional groups.
The FT-IR spectra of the samples are illustrated in Fig. 4. Both HTC and HTC-s had a board absorption band at $3000-3600 \mathrm{~cm}^{-1}$, attributed to $\mathrm{OH}$ stretching vibration in the hydroxyl or carboxyl groups. However, the centre of 
Fig. 3 Response surface and contour plots for the effects of the carbonation time and the carbonation temperature on the surface acidity
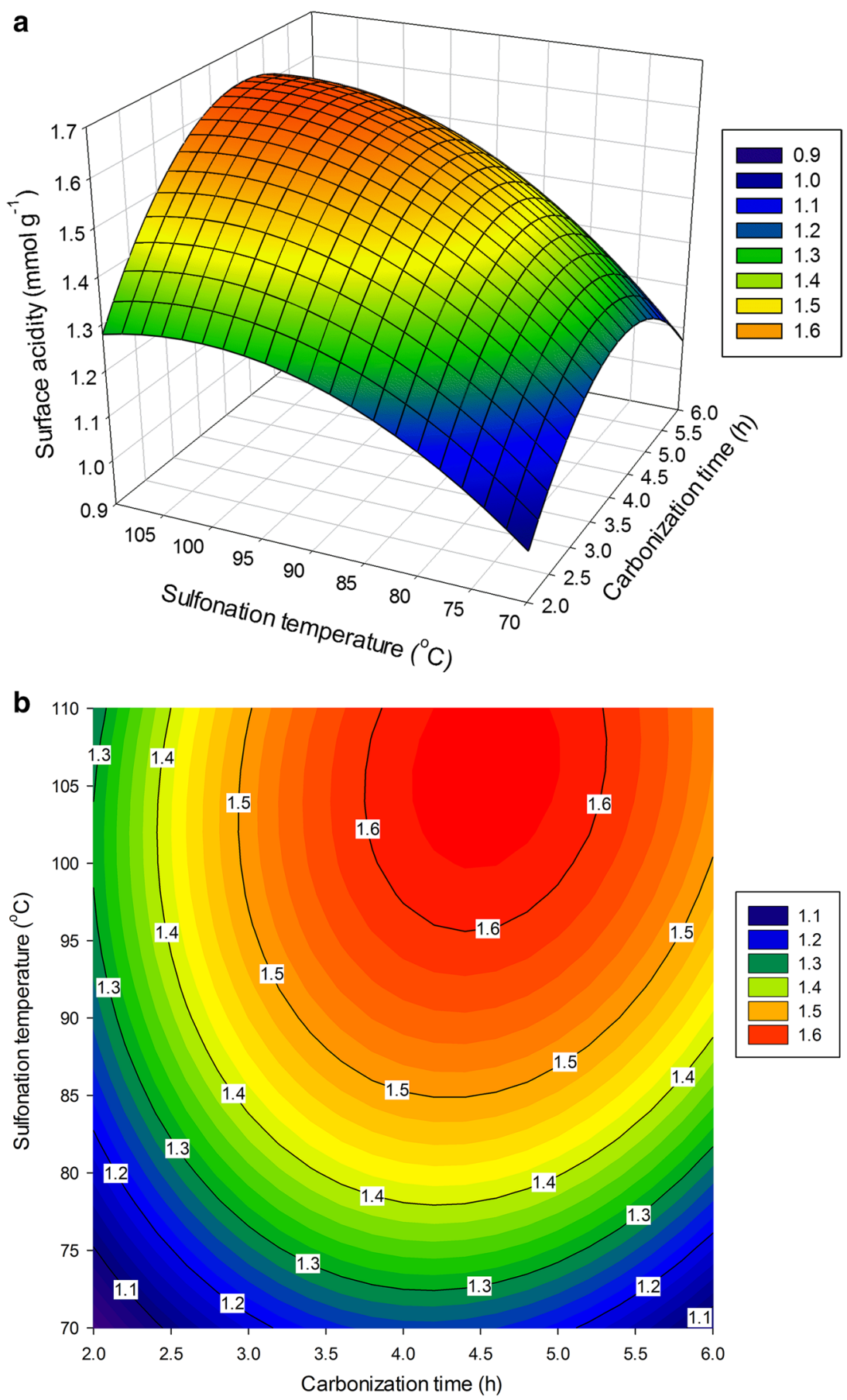

the band was shifted from $3341 \mathrm{~cm}^{-1}$ for the hydrochar to $3402 \mathrm{~cm}^{-1}$ for the sulfonated sample. The same phenomena was observed by Ma et al. [6].

The hydrochar had stronger absorption bands at $3000-2800 \mathrm{~cm}^{-1}$, which attributes to stretching vibrations of aliphatic $\mathrm{C}-\mathrm{H}$. After sulfonation, the strength of the peaks reduced, while the peak at $3010 \mathrm{~cm}^{-1}$ became more visible which is attributed to $\mathrm{C}-\mathrm{H}$ vibration of the aromatic ring. It indicated that aliphatic hydrocarbon was converted into aromatic compounds during the sulfonated process. New peaks 
Table 6 Elemental analysis of S. horneri, hydrochar (HTC) and sulfonated hydrochar (HTC-S)

\begin{tabular}{lllllll}
\hline Sample & \multicolumn{3}{l}{ Mass composition $(\%)$} & \multicolumn{2}{l}{ Chemical formula } \\
\cline { 2 - 5 } & $\mathrm{C}$ & $\mathrm{H}$ & $\mathrm{O}$ & $\mathrm{N}$ & $\mathrm{S}$ & \\
\hline S. horneri & 35.3 & 5.7 & 56.3 & 1.7 & 1.0 & $\mathrm{CH}_{1.450} \mathrm{O}_{0.894} \mathrm{~N}_{0.030} \mathrm{~S}_{0.008}$ \\
HTC & 50.9 & 4.9 & 41.0 & 2.2 & 1.0 & $\mathrm{CH}_{1.150} \mathrm{O}_{0.604} \mathrm{~N}_{0.037} \mathrm{~S}_{0.007}$ \\
HTC-S & 42.3 & 4.0 & 46.8 & 1.5 & 5.4 & $\mathrm{CH}_{1.140} \mathrm{O}_{0.830} \mathrm{~N}_{0.030} \mathrm{~S}_{0.048}$ \\
\hline
\end{tabular}

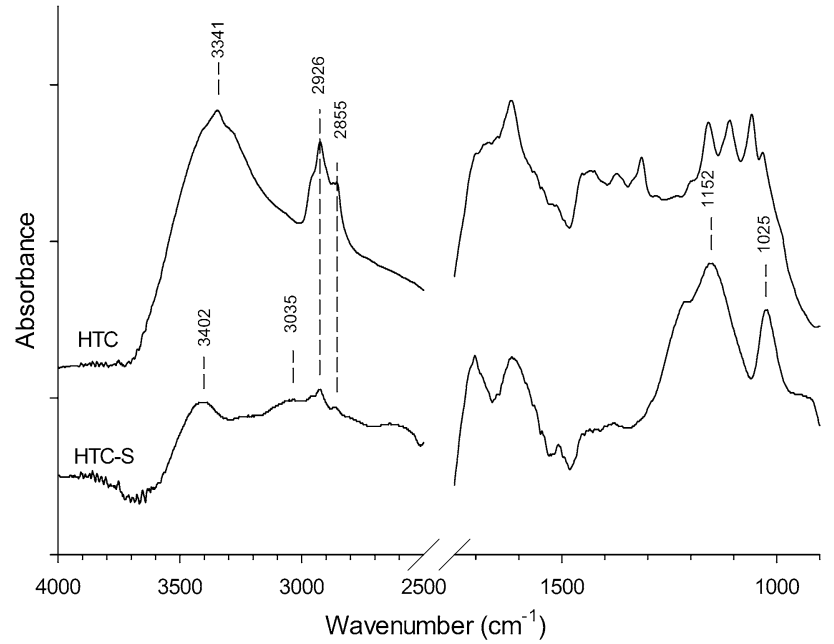

Fig. 4 FT-IR spectra of hydrochar (HTC) and sulfonated hydrochar (HTC-S)

assigned to $\mathrm{O}=\mathrm{S}=\mathrm{O}$ symmetric stretching and $\mathrm{SO}_{3}$ stretching modes appeared at 1025 and $1152 \mathrm{~cm}^{-1}$. It further indicates that $\mathrm{SO}_{3} \mathrm{H}$ groups were introduced onto the hydrochars.

The PXRD patterns for the HTC and HTC-S samples are shown in Fig. 5. Both HTC and HTC-S had a broad (002) diffraction peak at the $2 \theta$ of $23^{\circ}$, which is attributable to amorphous carbon composed of aromatic carbon sheets oriented in a considerably random fashion [24]. After sulfonation, the (002) peak became sharper and moved from $22.76^{\circ}$ to $23.05^{\circ}$. The observation suggested that the carbon structure became more organized due to the sulfonation. In the PXRD pattern for HTC-S, the peaks for $\mathrm{CaSO}_{4}$ crystals were observed. It was due to high concentration of calcium ions presented in macro-algae.

\section{Performance of Solid Acid Catalyst}

The catalytic activity of the prepared solid acid catalyst was first tested by the esterification of oleic acid and methanol. At $90{ }^{\circ} \mathrm{C}$ and $2.7 \mathrm{~h}$, the reaction achieved $96.6 \%$ esterification yield using HTC-S. For comparison, Amberlyst-15 was used as the benchmark. At the same reaction conditions, the reaction achieved a yield of $86.7 \%$ using

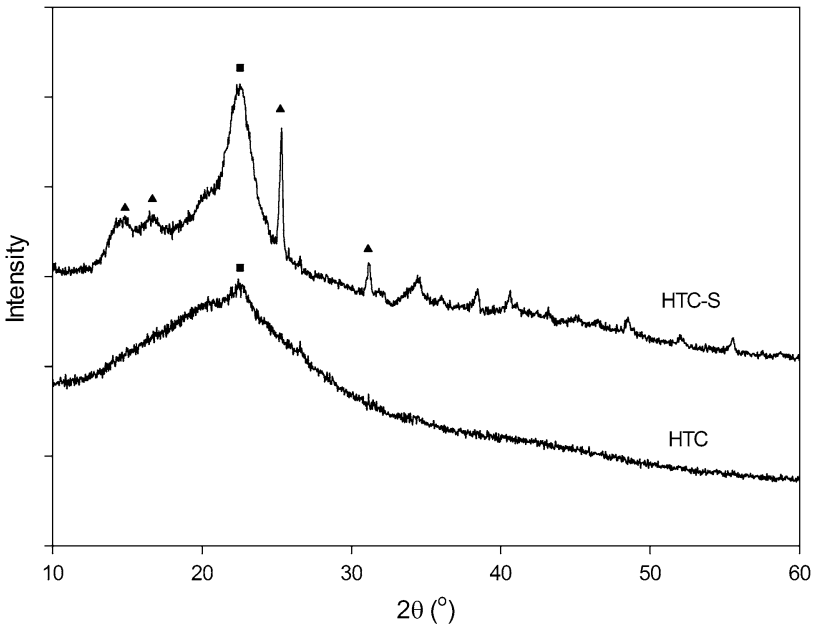

Fig. 5 PXRD patterns of hydrochar (HTC) and sulfonated hydrochar (HTC-S). (Filled square) amorphous carbon, (filled triangle) $\mathrm{CaSO}_{4}$

Amberlyst-15. It shown that the biomass based HTC-S had higher activity for esterification of oleic acid and methanol than Amberlyst-15.

The solid acid catalyst was also tested for its ability to be reused. The catalyst was separated from the reaction medium, washed, dried and then reused. The esterification yield reduced from 96.6 to $85.1 \%$ after being reused seven times (Fig. 6). The surface acidity was reduced after each use, from 1.62 to $0.82 \mathrm{mmol} \mathrm{g}^{-1}$. It indicated that part of the surface acid groups are soluble in solvent.

\section{Conclusions}

The optimal preparation condition of Sargassum horneri derived solid acid catalyst were at a carbonization temperature of $217^{\circ} \mathrm{C}$, carbonization time of $4.6 \mathrm{~h}$, concentrated sulfuric acid volume of $15 \mathrm{~mL}$, the sulfonation temperature of $108.5^{\circ} \mathrm{C}$ and sulfonation time of $2 \mathrm{~h}$. Under this condition, the surface acidity measured by experiment could reach $1.62 \mathrm{mmol} \mathrm{g}^{-1}$.

The results of crystal structure analysis, elemental analysis and surface functional group analysis indicated that the sulfonic acid group was successfully loaded onto the 
Fig. 6 Reusability of the HTC-S prepared under the optimized conditions

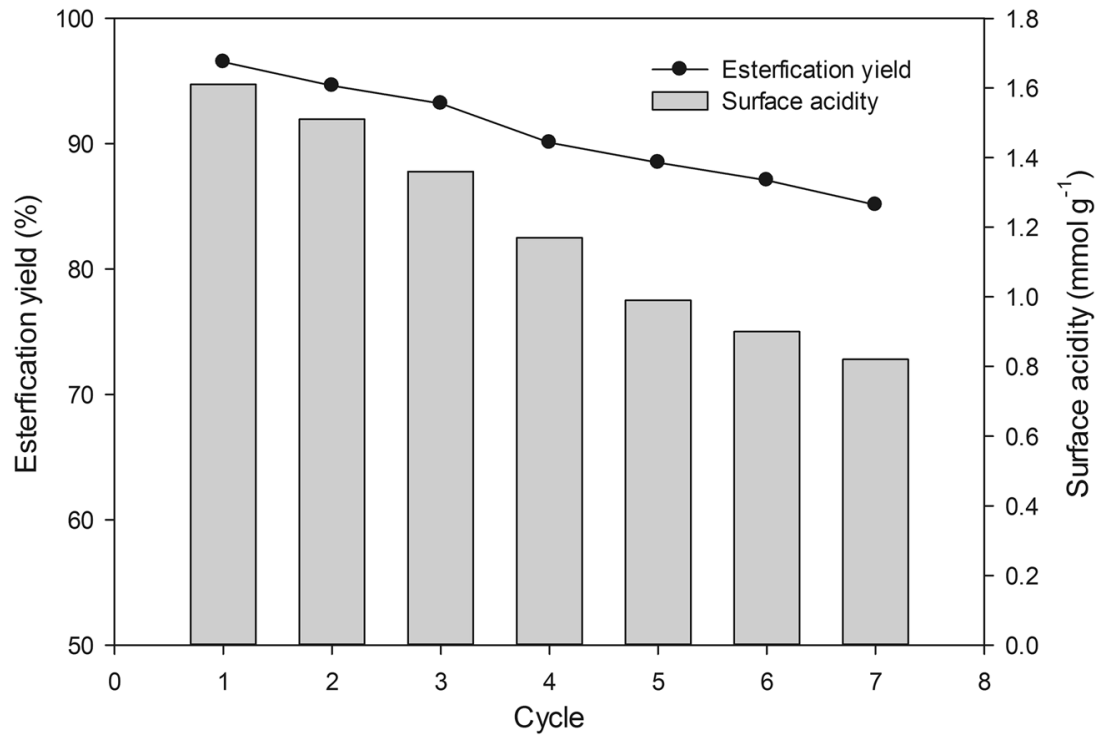

surface of an amorphous carbon structure. The catalyst activity test showed that the macroalgae derived solid acid catalysts had high catalyst activity.

Acknowledgements MJJ would like to acknowledge the support from Programme Erasmus Plus for Traineeships. NA thank the Zhejiang Provincial Natural Science Foundation of China (LY16B060014) and the Zhejiang ocean economic innovation achievements transformation and industrialization of development area demonstration projects (2015-83) for their finance support.

Open Access This article is distributed under the terms of the Creative Commons Attribution 4.0 International License (http://creativecommons.org/licenses/by/4.0/), which permits use, duplication, adaptation, distribution and reproduction in any medium or format, as long as you give appropriate credit to the original author(s) and the source, provide a link to the Creative Commons license and indicate if changes were made.

\section{References}

1. Okuhara, T.: Water-tolerant solid acid catalysts. Chem. Rev. 102, 3641-3666 (2002)

2. Tanabe, K., Holderrich, W.F.: Industrial application of solid acidbase catalysts. Appl. Catal. A Gen. 181, 399-434 (1999)

3. Kastner, J.R., Miller, J., Geller, D.P., Locklin, J., Keith, L.H., Johnson, T.: Catalytic esterification of fatty acids using solid acid catalysts generated from biochar and activated carbon. Catal. Today. 190, 122-132 (2012)

4. Li, M., Chen, D., Zhu, X.: Preparation of solid acid catalyst from rice husk char and its catalytic performance in esterification. Chin. J. Catal. 34, 1674-1682 (2013)

5. Liu, T., Li, Z., Li, W., Shi, C., Wang, Y.: Preparation and characterization of biomass carbon-based solid acid catalyst for the esterification of oleic acid with methanol. Bioresour. Technol. 133, 618-621 (2013)

6. Ma, H., Li, J., Liu, W., Cheng, B., Cao, X., Mao, J., Zhu, S.: Hydrothermal preparation and characterization of novel corncob-derived solid acid catalysts. J. Agric. Food Chem. 62, 5345-5353 (2014)

7. Wang, L., Dong, X., Jiang, H., Li, G., Zhang, M.: Preparation of a novel carbon-based solid acid from cassava stillage residue and its use for the esterification of free fatty acids in waste cooking oil. Bioresour. Technol. 158, 392-395 (2014)

8. Lou, W.Y., Guo, Q., Chen, W.J., Zong, M.H., Wu, H., Smith, T.J.: A highly active bagasse-derived solid acid catalyst with properties suitable for production of biodiesel. ChemSusChem. 5, 1533-1541 (2012)

9. Ezebor, F., Khairuddean, M., Abdullah, A.Z., Boey, P.L.: Esterification of oily-FFA and transesterification of high FFA waste oils using novel palm trunk and bagasse-derived catalysts. Energy Convers. Manag. 88, 1143-1150 (2014)

10. Fu, X., Li, D., Chen, J., Zhang, Y., Huang, W., Zhu, Y., Yang, J., Zhang, C.: A microalgae residue based carbon solid acid catalyst for biodiesel production. Bioresour. Technol. 146, 767-770 (2013)

11. Liu, R.L., Gao, X.Y., An, L., Ma, J., Zhang, J.F., Zhang, Z.Q.: Fabrication of magnetic carbonaceous solid acids from banana peel for the esterification of oleic acid. RSC Adv. 5, 93858-93866 (2015)

12. Chi, G., Hu, S., Yang, Y., Chen, T.: Response surface methodology with prediction uncertainty: a multi-objective optimisation approach. Chem. Eng. Res. Des. 90(9), 1235-1244 (2012)

13. Asfaram, A., Ghaedi, M., Agarwal, S., Tyagi, I., Gupta, V.K.: Removal of basic dye Auramine-O by $\mathrm{ZnS}$ : $\mathrm{Cu}$ nanoparticles loaded on activated carbon: optimization of parameters using response surface methodology with central composite design. RSC Adv. 5(24), 18438-18450 (2015)

14. Mohammadi, R., Mohammadifar, M.A., Mortazavian, A.M., Rouhi, M., Ghasemi, J.B., Delshadian, Z.: Extraction optimization of pepsin-soluble collagen from eggshell membrane by response surface methodology (RSM). Food Chem. 190, 186-193 (2016)

15. Ferreira, S.L.C., Bruns, R.E., Ferreira, H.S., Matos, G.D., David, J.M., Brandão, G.C., da Silva, E.G.P., Portugal, L.A., dos Reis, P.S., Souza, A.S., dos Santos, W.N.L.: Box-Behnken design: an alternative for the optimization of analytical methods. Anal. Chim. Acta. 597, 179-186 (2007)

16. Prakash Maran, J., Manikandan, S., Mekala, V.: Modeling and optimization of betalain extraction from Opuntia ficus-indica using Box-Behnken design with desirability function. Ind. Crops Prod. 49, 304-311 (2013) 
17. Jeganathan, P.M., Venkatachalam, S., Karichappan, T., Ramasamy, S.: Model development and process optimization for solvent extraction of polyphenols from red grapes using BoxBehnken design. Prep. Biochem. Biotechnol. 44, 56-67 (2014)

18. Yetilmezsoy, K., Demirel, S., Vanderbei, R.J.: Response surface modeling of $\mathrm{Pb}$ (II) removal from aqueous solution by Pistacia vera $\mathrm{L}$.: Box-Behnken experimental design. J. Hazard. Mater. 171, 551-562 (2009)

19. Tripathi, P., Srivastava, V.C., Kumar, A.: Optimization of an azo dye batch adsorption parameters using Box-Behnken design. Desalination. 249, 1273-1279 (2009)

20. Gu, T., Chen, Z., Jiang, X., Zhou, L., Liao, Y., Duan, M., Wang, $\mathrm{H}$., Pu, Q.: Synthesis and inhibition of $N$-alkyl-2-(4-hydroxybut2-ynyl) pyridinium bromide for mild steel in acid solution: BoxBehnken design optimization and mechanism probe. Corros. Sci. 90, 118-132 (2015)

21. Bagheri, A., Taghizadeh, M., Behbahani, M., Akbar Asgharinezhad, A., Salarian, M., Dehghani, A., Ebrahimzadeh, H., Amini,
M.M.: Synthesis and characterization of magnetic metal-organic framework (MOF) as a novel sorbent, and its optimization by experimental design methodology for determination of palladium in environmental samples. Talanta. 99, 132-139 (2012)

22. Xu, Q., Qian, Q., Quek, A., Ai, N., Zeng, G., Wang, J.: Hydrothermal carbonization of macroalgae and the effects of experimental parameters on the properties of hydrochars. ACS Sustain. Chem. Eng. 1, 1092-1101 (2013)

23. Aslan, N., Cebeci, Y.: Application of Box-Behnken design and response surface methodology for modeling of some Turkish coals. Fuel. 86, 90-97 (2007)

24. Suganuma, S., Nakajima, K., Kitano, M., Yamaguchi, D., Kato, H., Hayashi, S.: Hydrolysis of cellulose by amorphous carbon bearing $\mathrm{SO} 3 \mathrm{H}, \mathrm{COOH}$, and $\mathrm{OH}$ groups. J. Am. Chem. Soc. 130, 12787-12793 (2008)

\section{Affiliations}

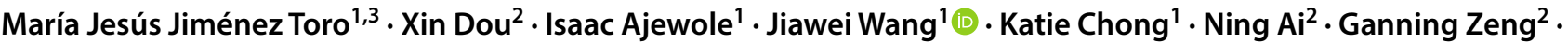 Tao Chen ${ }^{4}$}

1 European Bioenergy Research Institute, Aston University, Aston Triangle, Birmingham B4 7ET, UK

2 Zhejiang Province Key Laboratory of Biomass Fuel, College of Chemical Engineering, Zhejiang University of Technology, Hangzhou 310014, China
3 Chemical Engineering Department, Faculty of Sciences, University of Granada, Avda. Fuentenueva s/n, Granada 18071, Spain

4 Department of Chemical and Process Engineering, University of Surrey, Guildford GU2 7XH, UK 